\title{
TOWARD A SYSTEMATIC APPROACH TO THE STUDY OF COMPLEX HUMAN FUNCTIONING
}

\author{
AARON J. BROWNSTEIN and RICHARD L. SHULL \\ University of North Carolina at Greensboro
}

The presentation was based on a paper that has since been published (Brownstein and Shull, 1985). An abstract only of the presentation follows.

A trend is apparent within the experimental analysis of behavior toward increasing concern with the analysis of complex human behavior. While this effort certainly is laudable, there are danger signs. The danger is that this subfield, which now is in a period of rapid and enthusiastic growth, may lose its connection with the core science from which it emerged. The result could be an unsystematic proliferation of terms and concepts with vague defining properties and for which relations with more traditional behavioral terms and concepts are obscure. To the extent that one values a systematic, coherent science, one surely would view such a development as unfortunate.

Sometimes a new term is introduced into a behavioral interpretation because the term delineates a set of phenomena of practical interest or of interest to nonbehavioral psychologists. The point then is to show how the phenomena so identified can be interpreted as instances of a larger, familiar class or to show how the phenomena can be interpreted in terms of the familiar classes of controlling relations. What sometimes happens, however, is that the newly introduced term comes to function as if it were a technical term in the experimental analysis of behavior, on a par with the technical terms that were used in the interpretation of the identified phenomena. Technical terms are the necessary elements that enable analyses of complex events. They reflect independent sources of control that complement each other. As we move from one arena of concern to another, the terms may be further differentiated as a result of bringing the analysis into contact with elements of concern to those involved primarily in that arena. For example, several different forms of discriminated operants are identified in Verbal Behavior (Skinner, 1957) such as echoics, tacts, and textuals along with a form of nondiscriminated operant, the mand. It would be most unfortunate if one were to make the category error of concluding that echoics, textuals, tacts, and mands were necessary additional terms in an experimental analysis of behavior with a role comparable to that of discriminated and nondiscriminated operants.

The paper discusses the use ot term, "rule-governed behavior," as exemplifying these potential problems.

This abstract was prepared by R. L. Shull after Aaron Brownstein's untimely death.

\section{References}

BROWNSTEIN, A. J., \& SHULL, R. L. (1985). On terms: A rule for the use of the term, "rulegoverned behavior." The Behavior Analyst, 8, 265-267.

SKINNER, B. F. (1957). Verbal behavior. New York: Appleton-Century-Crofts. 